\title{
Review Article \\ Research Progress on Regulatory T Cells in Acute Kidney Injury
}

\author{
Yamei Wang ${ }^{1,2}$ and Yuhong Tao ${ }^{1}$ \\ ${ }^{1}$ Department of Pediatrics, West China Second University Hospital, Sichuan University, Chengdu 610041, China \\ ${ }^{2}$ Key Laboratory of Birth Defects and Related Diseases of Women and Children (Sichuan University), \\ Ministry of Education, Chengdu 610041, China
}

Correspondence should be addressed to Yuhong Tao; hxtyh@sina.com

Received 14 May 2015; Accepted 2 July 2015

Academic Editor: Eyad Elkord

Copyright (C) 2015 Y. Wang and Y. Tao. This is an open access article distributed under the Creative Commons Attribution License, which permits unrestricted use, distribution, and reproduction in any medium, provided the original work is properly cited.

\begin{abstract}
Immune inflammation is crucial in mediating acute kidney injury (AKI). Immune cells of both the innate and adaptive immune systems substantially contribute to overall renal damage in AKI. Regulatory T cells (Tregs) are key regulator of immunological function and have been demonstrated to ameliorate injury in several murine experimental models of renal inflammation. Recent studies have illuminated the renal-protective function of Tregs in AKI. Tregs appear to exert beneficial effects in both the acute injury phase and the recovery phase of AKI. Additionally, Tregs-based immunotherapy may represent a promising approach to ameliorate AKI and promote recovery from AKI. This review will highlight the recent insights into the role of Tregs and their therapeutic potential in AKI.
\end{abstract}

\section{Introduction}

Acute kidney injury (AKI) is caused by multiple etiologies that lead to renal dysfunction within a short period of time. Ischaemia reperfusion injury (IRI), nephrotoxic agents, and sepsis are among the major causes of AKI. AKI occurs in $5 \%$ of hospitalized patients or $30 \%$ of critically ill patients, with detrimental consequences in terms of morbidity and mortality $[1,2]$. Additionally, AKI increases the likelihood of developing chronic kidney disease and end-stage renal disease $[3,4]$. Despite remarkable advances in blood purification, AKI remains to be a significant challenge that lacks specific tools to reduce kidney damage and promote kidney repair.

The pathogenesis of AKI is complex. Previous studies have revealed that immune inflammation is crucial in mediating AKI [5]. Immune cells of both the innate and adaptive immune systems, including dendritic cells (DCs), natural killer T cells, $\mathrm{T}$ and $\mathrm{B}$ lymphocytes, neutrophils, and macrophages, are well known for their participation in early injury [6]. Therefore, control of kidney inflammation can significantly reduce kidney damage in AKI $[7,8]$. Removing, inhibiting, or antagonizing neutrophils, macrophages, T cells, and B lymphocytes have been shown to suppress renal inflammation and protect in vivo AKI models to varying degrees [9].
Regulatory $\mathrm{T}$ cells (Tregs) are a subset of $\mathrm{CD} 4^{+} \mathrm{T}$ cells expressing the IL-2 receptor (CD25) and Forkhead Box P3 (Foxp3), a transcriptional factor that regulates the immunosuppressive activity of Tregs. Foxp $3^{+}$Tregs account for approximately $2 \%$ of the total number of mononuclear cells in the normal kidney [6]. Tregs have inhibitory roles in various kidney diseases that include nephrotic syndrome, lupus nephritis, diabetic nephropathy, hypertensive renal injury, and other kidney diseases [10]. Recently, some studies have indicated that Tregs are protective and have become a potential target of AKI immunotherapy. In this review, we examine the research progress of Tregs in AKI.

\section{Tregs Overview}

Tregs are a developmentally and functionally distinct $\mathrm{T}$ cell subpopulation that is engaged in sustaining immunological self-tolerance and homeostasis [11, 12]. Natural Tregs (nTregs) are derived centrally in the thymus in response to selfantigens and regulate peripheral tolerance. Inducible Tregs (iTregs) are induced in the periphery from naïve $\mathrm{T}$ cells upon antigenic stimulation in the presence of transforming growth factor- $\beta$ (TGF- $\beta$ ) and IL-2. Activation and migration of Tregs into tissue are critical for the control of inflammation 


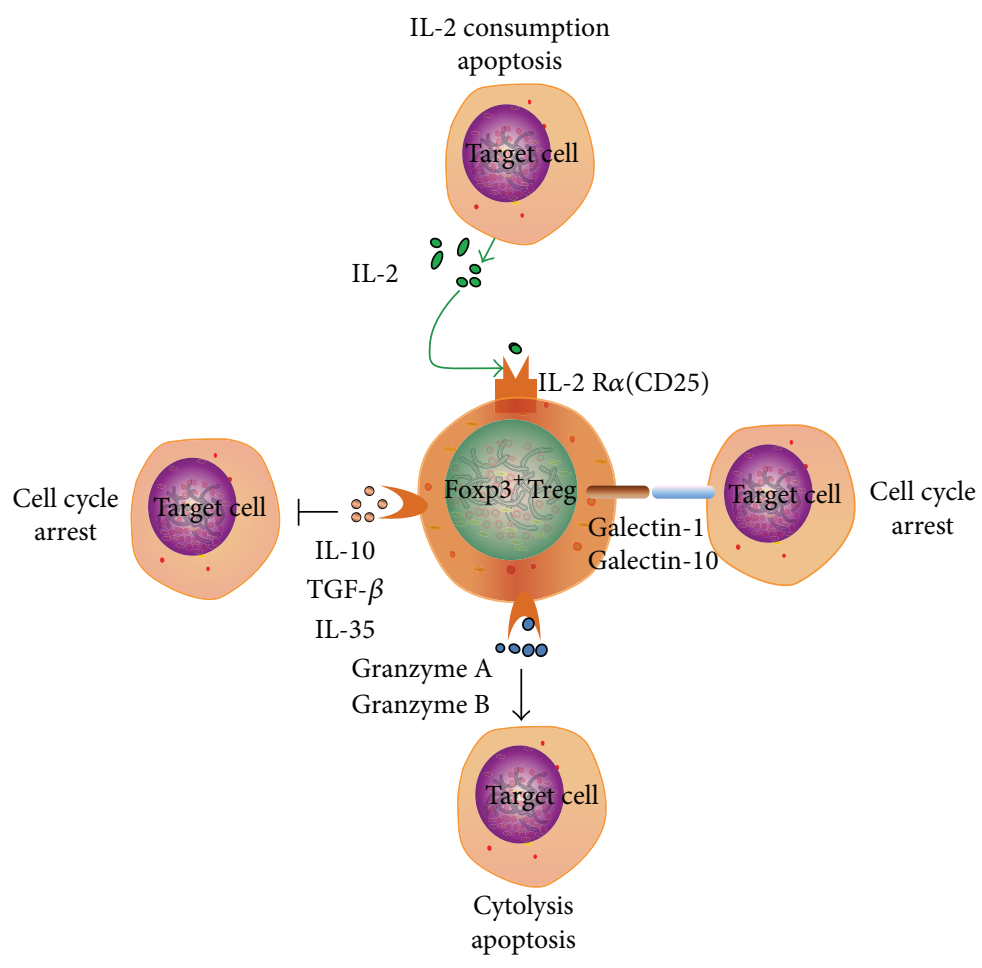

(a) Suppress responder Foxp $3^{-} \mathrm{T}$ cells

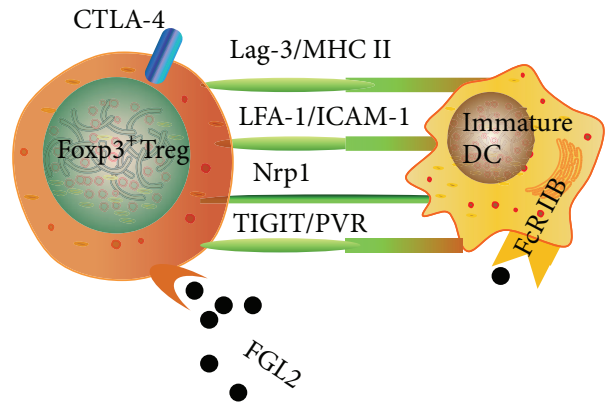

(b) Decrease costimulation

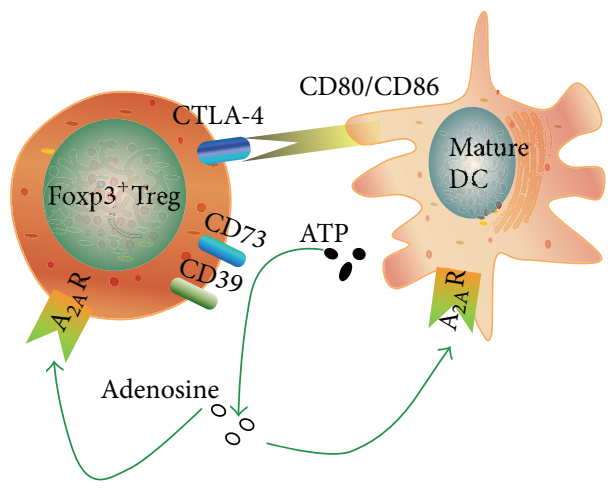

(c) Decrease antigen presentation

FIgURE 1: The mechanisms by which Tregs suppress the immune response. The main mechanisms include those that target Foxp $3^{-} \mathrm{T}$ cells (cell cycle arrest, IL-2 consumption, apoptosis, and cytolysis) and those that primarily target dendritic cells (decreased costimulation or decreased antigen presentation).

[13]. Like conventional $\mathrm{T}$ cells, Tregs require $\mathrm{T}$ cell receptor stimulation and costimulation for activation [14]. Circulating and tissue iTregs numbers depend on anatomic location and the specific inflammatory environment. Constitutive expression of adhesion molecules (e.g., integrin $\alpha \mathrm{E}$, CD62L, $\mathrm{CD} 44$, and selectin ligands) and chemokine receptors (e.g., CCR2, CCR4, CCR5, CCR6, CCR7, and chemokine C-X-C motif receptor 3) [15-17] mediate the migration of Tregs into the inflammation site $[18,19]$, where Tregs suppress the innate and adaptive immune response through contact-dependent and soluble mediators.

First, Tregs may target Foxp $3^{-} \mathrm{T}$ cells (Figure 1(a)). Tregs secrete suppressor cytokines (e.g., IL-10, TGF- $\beta$, and IL-35) that can directly result in inhibiting the function of Foxp $3^{-} \mathrm{T}$ cells and cell cycle arrest [20]. In addition, Tregs suppress the proliferation of effector $T$ cells by upregulating the expression of CD25 [21] and competing with effector T cells to deplete IL2 [22], which ultimately induces apoptosis of effector T cells via a tumor necrosis factor-related apoptosis-inducing ligand [23]. Activated Tregs also express other soluble mediators, such as galectin-1, galectin-10 [24, 25], granzyme A, and granzyme B [26, 27], which can interact with effector $\mathrm{T}$ cells, resulting in cell cycle arrest, apoptosis, or cytosis.

Second, Tregs may primarily target DCs to decrease costimulation or antigen presentation (Figures 1(b) and 1(c)). Most Tregs express the cytotoxic $\mathrm{T}$ cell surface-associated 
antigen 4 (CTLA-4) on their surface [28, 29]. Tregs maintain close interaction with immature DCs through lymphocyte activation gene-3 (Lag-3)/MHC II molecules [30], leukocyte function-associated antigen-1 (LFA-1)/intercellular adhesion molecule 1 (ICAM-1) [31], and neuropilin-1 (Nrp1) [32] on their cell surface and rely on CTLA- 4 to inhibit the maturation of DCs [33]. Lag-3 on Tregs can interact with MHC II molecules on immature DCs and results in an inhibitory signal that suppresses DC maturation and immunostimulatory capacity. Nrp-1 promotes long interactions between Tregs and immature DCs and restricts access of the effector T cells to DCs. Tregs expressing the $\mathrm{T}$ cell immunoreceptor with Ig and ITIM domains (TIGIT) are combined with the poliovirus receptor (PVR) on the surface of DCs, which induce DCs to produce IL-10 and TGF- $\beta$ for immune suppression [34]. Tregs secreting fibrinogen-like protein 2 (FGL2) combined with low affinity Fc receptor type IIB (FcR IIB) inhibit the maturation of DCs [35]. In FGL2 knockout (KO) mice, the number of DCs increased with the stimulation of lipopolysaccharide, upregulation of CD80 and MHC II molecules, and the subsequent increase in the number of Tregs [36]. CTLA4 on the surface of Tregs prevents the upregulation of CD80/CD86 on mature DCs and decreases antigen presentation [37] (Figure 1(c)). The ATP released from damaged cells induces the activation and inflammation of DCs. Tregs express high levels of CD39 (ectonucleoside triphosphate dephosphorylase 1) and CD73 (ecto-5' -nucleotidase) that convert extracellular ATP to adenosine [38], which has anti-inflammatory effects through adenosine $2 \mathrm{~A}$ receptors $\left(A_{2 A} R s\right)$. Tregs generated adenosine signal through $A_{2 A}$ Rs on inflammatory cells and in an autocrine manner on Tregs themselves [39]. In addition, activation of $\mathrm{A}_{2 \mathrm{~A}}$ Rs on mature DCs resulted in enhanced CD54, CD80, MHC I molecules, and HLA-DR molecule expression as well as a dose-dependent inhibition of TNF- $\alpha$ and IL-12 and augmentation of IL-10 secretion [40].

\section{Roles of Tregs in AKI}

3.1. Tregs in Ischemic AKI. Kinsey et al. [41] used an antiCD25 monoclonal antibody (PC61) to partially deplete Tregs in an in vivo mouse model 5 days prior to kidney IRI. Twentyfour hours after renal IRI, nephritis, tubular necrosis, and renal function declined in PC61-treated mice, changes that were significantly greater than those observed in control mice. Reducing the number of Tregs resulted in more neutrophils, macrophages, and innate immune system cytokines (i.e., IL-6, tumor necrosis factor- $\alpha$ (TNF- $\alpha$ ), and TGF- $\beta$ ) in the kidney after IRI but did not affect $\mathrm{CD} 4^{+} \mathrm{T}$ cells or $B$ cells. Kinsey et al. [41] also performed adoptive transfer of lymph node cells from wild type (WT) mice or Scurfy mice (Foxp3-deficient mice) into RAG-1 KO mice (T cell and $\mathrm{B}$ cell-deficient mice) to generate mice with and without Foxp $3^{+}$Tregs, respectively. The Foxp $3^{+}$Treg-deficient mice accumulated a higher number of inflammatory leukocytes after renal IRI than mice containing Tregs. Moreover, this increased renal damage was reversed by isolated WT Tregs transfer to the Scurfy lymph node cells in the RAG-1
KO model. Therefore, Tregs regulated the inflammatory responses of innate immunity at the early stage of renal IRI and alleviated kidney damage.

Monteiro et al. [42] used PC61 prior to renal IRI in a mouse model. In this study, seventy-two hours after renal IRI the kidney function declined, and kidney damage was markedly exacerbated, which suggested that Tregs alleviate kidney damage. Gandolfo et al. [43] revealed that Tregs depletion using PC61, starting one day after renal IRI, exacerbated renal tubular damage, reduced tubular proliferation, and increased cytokine production by infiltrating $\mathrm{T}$ cells on day 3 and increased TNF- $\alpha$ generation by $\mathrm{CD} 4^{+} \mathrm{T}$ cells on day 10. However, adoptive transfer of Tregs on day 1 after IRI resulted in reduced production of IFN- $\gamma$ by $\mathrm{CD} 4^{+} \mathrm{T}$ cells on day 3 and improved repair and reduced the generation of proinflammatory cytokines by day 10 [43]. Furthermore, during the repair phase, administration of mycophenolate mofetil reduced the total number of kidney mononuclear cells and decreased the population of Tregs, which inhibited recovery from renal IRI [44]. Jun et al. [45] also showed that $\mathrm{CD} 4^{+} \mathrm{CD} 25^{\text {high }} \mathrm{CD} 127^{\text {low }}$ Tregs expansion promoted kidney repair, and PC61 treatment aggravated kidney damage in a mouse renal IRI model. Collectively, Tregs traffic to the injured kidney may promote repair from renal IRI.

Ischemic preconditioning (IPC) is a stronger measure of protecting the kidneys from IRI [46]. IPC is partially mediated by Tregs and significantly inhibits the accumulation of neutrophils and macrophages, tubular necrosis, and loss of kidney function caused by a subsequent renal IRI one week later [47]. PC61 treatment before the second ischemia in IPC mice resulted in a decrease [48] or complete inhibition of the renal-protective effect of IPC [49]. Thus, Tregs might be involved in IPC-induced renal protection.

3.2. Tregs in Nephrotoxic AKI. The renoprotective effects of Tregs have also been found in models of nephrotoxic AKI. In experimental murine AKI induced by cisplatin [50], the adoptive transfer of Tregs attenuated renal injury and decreased macrophage infiltration in both (mature-T-celldeficient) Foxn $1^{n u / n u}$ mice and WT Balb/c mice. Consistently, Tregs depletion with PC61 before cisplatin administration resulted in worse renal function and tissue injury.

3.3. Tregs in Septic AKI. Sepsis is considered an excessive systemic inflammation. However, the pathogenesis of septic acute kidney injury is thought to be different from that of ischemia/reperfusion induced AKI. Furthermore, the inhibition of inflammation has been shown to have no effect on sepsis. In a mouse model of cecal ligation and puncture- (CLP-) induced sepsis, septic AKI was associated with an increase in IL-10 and increased Tregs [51]. In contrast to renal IRI, depletion of Tregs before CLP resulted in renoprotection [51]. Cho et al. [52] also showed that increases in serum soluble CD25 and IL-10 in patients with septic AKI were strongly associated with immunosuppression. Hence, Tregs may contribute to septic AKI. 


\section{The Action Mechanism of Tregs in AKI}

Although Tregs utilize various mechanisms to suppress renal inflammation in AKI, there are many questions that need to be answered regarding the action mechanism of Tregs in AKI. To date, most of the mechanisms depicted above still have not been investigated in AKI models. IL-10 is a potent antiinflammatory cytokine that inhibits inflammatory pathways [53]. Kinsey et al. [41] found that RAG-1 KO mice exposed to more prolonged renal IRI were protected by the adoptive transfer of WT Tregs. However, this protective effect was lost if IL-10 KO Tregs were administered, thus implicating IL-10 as a key mediator of Tregs protection. In the study of Gandolfo et al. [43], the role of IL-10 production by Tregs remained unclear, as IL-10 expression was markedly increased in the aftermath of Tregs depletion in the recovery phase of renal IRI. Kinsey et al. [54] demonstrated that adoptively transferred WT Tregs protected WT mice from kidney IRI, but CD73-deficient Tregs or $\mathrm{A}_{2 \mathrm{~A}}$ Rs-deficient Tregs led to the inhibition of Tregs function. $\mathrm{A}_{2 \mathrm{~A}}$ Rs activation can enhance the expression of programmed cell death 1 (PD-1) on the cell surface of Tregs. However, the blockade of PD-1, prior to adoptive transfer, negates their ability to protect against ischemic AKI [54]. Additionally, both PD-1 ligands (PD-L1 and PD-L2) protect the kidney from IRI [55]. Collectively, these results demonstrate that IL-10, adenosine, $\mathrm{A}_{2 \mathrm{~A}} \mathrm{Rs}$, and PD-1 are required for Tregs to suppress immune responses in renal IRI. In addition, both the CTLA- 4 and Tregs are essential for the control of immune homeostasis. Tregs commonly use CTLA4 to affect suppression [56]. However, previous research has shown that the use of an anti-CTLA- 4 antibody treatment counteracted the protection from renal IRI induced by N,N-dimethylsphingosine (DMS) [57], suggesting that CTLA-4 is also involved in the protective effects of Tregs in AKI.

\section{New Treatment Strategies for AKI Using Tregs}

5.1. Adoptive Transfer of $C D 4^{+} C D 25^{+}$Tregs. Tregs are the new targets for AKI immunotherapy $[8,58]$, and the most direct method is the adoptive transfer of Tregs [59]. Previous studies have indicated that autologous and donor-derived Tregs have similar protective effects on animal models with intestinal IRI [59], stroke [60], and burns [61]. Tregs adoptive immunotherapy can also alleviate kidney damage in animal models with adriamycin-induced nephropathy [62], antiglomerular basement membrane nephritis [63], and lupus nephritis [64]. Prior to renal ischemia [41] and cisplatin treatment [50], the transfer of freshly isolated $\mathrm{CD} 4^{+} \mathrm{CD} 25^{+}$Tregs $\left(1 \times 10^{6}\right.$ cells/mouse) from a normal WT mouse spleen to an AKI mouse model alleviated kidney damage and improved the survival rate of the AKI mice. In addition, the transfer of freshly isolated $\mathrm{CD} 4^{+} \mathrm{CD} 25^{+}$Tregs $\left(1 \times 10^{6}\right.$ cells/mouse $)$ from a normal WT mouse spleen to animals 24 hours after renal IRI increased the number of Tregs in the kidneys. A reduction in the production of TNF- $\alpha$ and IFN- $\gamma$ from effector T cells in the kidneys, improvement in tubular necrosis score, and acceleration of kidney repair were also observed. Although none of these reports have refuted the protective effect of adoptive transfer of Tregs in an aseptic AKI model [41, 43, 47, $50,54]$, various studies still dispute the therapeutic efficacy of adoptive transfer of Tregs [65].

Because adoptive transfer therapy requires a high number of Tregs, the in vitro amplification and induced production of Tregs using other methods is necessary. CD127 was recently discovered as an antigen that is associated with Tregs, although it is expressed at relatively low levels [66]. After magnetically activated cell sorting of $\mathrm{CD} 4^{+} \mathrm{CD} 25^{\text {high }} \mathrm{Foxp} 3^{+} \mathrm{T}$ cells, CD127 was used as a molecular marker for screening cells with highly expressed CD127 to significantly improve the purity of Tregs [67]. Application of the anti-CD3/CD28 monoclonal antibody-coated magnetic beads in the presence of 1,000-2,000 units of recombinant IL-2 effectively amplifies the $\mathrm{CD} 4{ }^{+} \mathrm{CD} 25^{+}$Tregs and inhibits $\mathrm{T}$ cell proliferation and cytokine production [59]. The addition of rapamycin and Accutane during in vitro cell culture also stabilizes the expression of Foxp3 in Tregs [68].

The current treatments of adoptive Tregs are mainly restricted to animal models and have not been confirmed in human AKI. However, Tregs adoptive immunotherapy in certain diseases has reached the clinical trial stage [69-71]. In 2011, Brunstein et al. [72] intravenously injected patients with in vitro amplified Tregs $\left(3 \times 10^{6}\right.$ cells $\left./ \mathrm{kg}\right)$ from umbilical cord blood after stem cell transplantation. As a result, a significantly reduced incidence of graft-versus-host disease was observed, whereas the risks of infection, primary disease recurrence, and early death did not increase. Thus, these studies have served as the foundation for Tregs adoptive immunotherapy in human AKI.

One of the most challenging problems of Tregs adoptive immunotherapy involves in vitro amplification of Tregs in normal T cells. Studies on the plasticity of T cell differentiation by Zhou et al. [73] prompted us to pay more attention to this possibility. Komatsu et al. [74] indicated that most adoptive Tregs could maintain their immunosuppressive activity. However, a small number of adoptive Tregs show a depletion of Foxp3 and a subsequent change to normal $\mathrm{T}$ cells, ultimately resulting in the restoration of pathogenicity. To date, the application of magnetic activated cell sorting to sort the enriched Tregs cannot completely remove the effector $\mathrm{T}$ cells, which results in a mixture of a large number of T lymphocytes in the in vitro amplified Tregs. Thus, the preservation of in vitro amplified Tregs has become a significant concern among researchers [75].

5.2. Targeting of Intrinsic Tregs. An alternative approach is to target intrinsic Tregs to enhance Tregs numbers, trafficking, or activity. Recently, several pharmaceutical agents that target intrinsic Tregs have been utilized in AKI models with encouraging results (Table 1). Bee venom and its constituent phospholipase A2 are capable of modulating Tregs in the spleens of mice [76]. Recently, Kim et al. [77] reported that bee venom had protective effects on cisplatin-induced nephrotoxicity in mice, at least in part, through increasing Tregs numbers and enhancing Tregs trafficking without a large influence 
TABle 1: Therapeutic strategies for AKI based on intrinsic Tregs.

\begin{tabular}{lccc}
\hline Reference & Animal model & Agent & In vivo effect \\
\hline Kim et al. [77] & Cisplatin-induced AKI & Bee venom & Tregs numbers \\
Tregs trafficking \\
Lai et al. [57] & Ischemic AKI & Dimethyl sphingosine & $\uparrow$ Tregs trafficking \\
Kim et al. [79] & Ischemic AKI & FTY720 & $\uparrow$ Tregs numbers \\
Kim et al. [81] & Ischemic AKI & IL-2/anti-IL-2 complexes & $\uparrow$ Tregs numbers \\
Baban et al. [82] & Ischemic AKI & Leflunomide & $\uparrow$ Tregs numbers \\
Hu et al. [86] & Ischemic AKI & Mesenchymal stem cells & $\uparrow$ Tregs numbers \\
Liang et al. [88] & Ischemic AKI & miR-26a & $\uparrow$ Tregs numbers \\
\hline
\end{tabular}

on the antitumor effects of cisplatin. Phospholipase A2 also prevented inflammatory responses in cisplatin-induced AKI by modulating Tregs and IL-10 through the CD206 mannose receptor [78]. Lai et al. [57] demonstrated that DMS, a naturally occurring sphingosine derivative, allowed Tregs to rapidly and transiently migrate to the kidneys, and pretreatment with DMS provided renoprotection in IRI. This DMSinduced renoprotection was abolished by the administration of agents that suppress Tregs or by anti-CTLA- 4 or antiCD45 monoclonal antibodies. However, another sphingosine kinase inhibitor did not produce similar protection. The sphingosine-1-phosphate analog (FTY720) is a new synthetic immunosuppressant that involves the structural transformation of the active ingredient of Cordyceps extract, myriocin. FTY720 exerts its immunosuppressive effects by reacting with the sphingosine-1-phosphate receptor on the cell surface. Treatment with FTY720 could attenuate renal IRI and reduce inflammation. The beneficial effects of FTY720 in renal IRI may be partially mediated by increasing Tregs activity [79]. The injection of IL-2/IL-2 monoclonal antibody $(\mathrm{mAb}) \mathrm{com}$ plexes into mice results in a 10-fold in vivo Tregs expansion [80]. Kim et al. [81] also showed that the IL-2/anti-IL-2 complexes administered before bilateral renal IRI, induced Tregs expansion in both the spleen and kidney, improved renal function, and attenuated renal injury and apoptosis after IRI. The aryl hydrocarbon receptor has emerged as a major modulator of inflammatory processes. The aryl hydrocarbon receptor agonist, leflunomide, increased Tregs and IL10-positive cells but reduced IL-17-expressing and IL-23expressing cells in both the peripheral blood and kidney cells in renal IRI mice [82]. Mesenchymal stem cells (MSCs) induced differentiation of naïve $\mathrm{T}$ cells through paracrine mechanisms [83] and promoted the in vivo amplification of Tregs [84, 85]. MSCs ameliorate renal IRI by inducing regulatory $\mathrm{T}$ cells through interactions with splenocytes. PC61 treatment or splenectomy reduced the renal-protective effect of MSCs [86]. miR-26a has been reported to play functions in cellular differentiation, cell growth, cell apoptosis, and metastasis [87]. Liang et al. [88] reported that miR-26a treatment induced significant expansion of Foxp $3^{+}$Tregs in both the spleen and kidneys on day 10 after IRI and attenuated renal IRI. Thus, these studies suggest that targeting intrinsic Tregs may be a promising option for AKI.

There are other therapeutic agents, such as ATL1222 ${ }^{\mathrm{b}}$ $\left(\mathrm{A}_{2 \mathrm{~A}} \mathrm{R}\right.$ agonist) [54], aspirin [89], and gardiquimod [90], which have been shown to enhance Tregs ex vivo or in vitro. However, none of them have been investigated with in vivo AKI models. With the development of assay platforms to screen for the Tregs modulating potential of pharmacological compounds [91], numerous novel agents will likely be found to boost Tregs number or activity in vivo.

\section{Conclusions}

Overall, Tregs have a renal-protective function through the suppression of renal inflammation, which is critical for blocking renal injury and/or promoting recovery from AKI. Based on the research in animal models, Tregs and their associated factors have been considered as potential therapeutic targets for AKI immunotherapy. An increasing understanding of Tregs' functional mechanisms in AKI will lead to a number of clinical trials on the discovery and development of new Tregsoriented therapies.

\section{Abbreviations}

$\mathrm{A}_{2 \mathrm{~A}} \mathrm{R}$ : Adenosine 2a receptors

AKI: Acute kidney injury

CLP: Cecal ligation and puncture

CTLA-4: Cytotoxic T cell surface-associated antigen 4

DCs: Dendritic cells

DMS: N,N-Dimethylsphingosine

FcR IIB: Fc receptor type IIB

FGL2: Fibrinogen-like protein 2

Foxp3: Forkhead Box P3

ICAM-1: Intercellular adhesion molecule 1

IPC: Ischemic preconditioning

IRI: Ischaemia reperfusion injury

iTregs: Inducible Tregs

KO: Knockout

Lag-3: Lymphocyte activation gene-3

LFA-1: Leukocyte function-associated antigen-1

MSCs: Mesenchymal stem cells

Nrp1: Neuropilin-1

nTregs: Natural Tregs

PD-1: $\quad$ Programmed cell death 1

PVR: $\quad$ Poliovirus receptor

TGF- $\beta$ : Transforming growth factor- $\beta$

TIGIT: T cell immunoreceptor with Ig and ITIM domains 
TNF- $\alpha$ : Tumor necrosis factor- $\alpha$

Tregs: Regulatory T cells

WT: Wild type.

\section{Conflict of Interests}

The authors declare that they have no conflict of interests regarding the publication of this paper.

\section{Authors' Contribution}

Yamei Wang made substantial contributions to the conception of the work and the drafting of the paper. Yuhong Tao provided substantial contributions to the design of the work and has critically revised the paper. All authors share in final approval of the version to be published.

\section{Acknowledgments}

This work was supported by the Application Foundation of Science and Technology of Sichuan Province (no. 2014JY0062 to Yuhong Tao). The authors also acknowledge American Journal Experts who corrected the paper and edited it for proper English.

\section{References}

[1] R. Bellomo, J. A. Kellum, and C. Ronco, "Acute kidney injury," The Lancet, vol. 380, no. 9843, pp. 756-766, 2012.

[2] O. Liangos, R. Wald, J. W. O’Bell, L. Price, B. J. Pereira, and B. L. Jaber, "Epidemiology and outcomes of acute renal failure in hospitalized patients: a national survey," Clinical Journal of the American Society of Nephrology, vol. 1, no. 1, pp. 43-51, 2006.

[3] L. S. Chawla and P. L. Kimmel, "Acute kidney injury and chronic kidney disease: an integrated clinical syndrome," Kidney International, vol. 82, no. 5, pp. 516-524, 2012.

[4] S. G. Coca, S. Singanamala, and C. R. Parikh, "Chronic kidney disease after acute kidney injury: a systematic review and metaanalysis," Kidney International, vol. 81, no. 5, pp. 442-448, 2012.

[5] M. N. Martina, S. Noel, S. Bandapalle, A. R. Hamad, and H. Rabb, "T lymphocytes and acute kidney injury: update," Nephron Clinical Practice, vol. 127, no. 1-4, pp. 51-55, 2014.

[6] G. R. Kinsey and M. D. Okusa, "Expanding role of T cells in acute kidney injury," Current Opinion in Nephrology and Hypertension, vol. 23, no. 1, pp. 9-16, 2014.

[7] G. R. Kinsey, L. Li, and M. D. Okusa, "Inflammation in acute kidney injury," Nephron: Experimental Nephrology, vol. 109, no. 4, pp. e102-e107, 2008.

[8] A. Bajwa, G. R. Kinsey, and M. D. Okusa, "Immune mechanisms and novel pharmacological therapies of acute kidney injury," Current Drug Targets, vol. 10, no. 12, pp. 1196-1204, 2009.

[9] J. V. Bonventre and L. Yang, "Cellular pathophysiology of ischemic acute kidney injury," The Journal of Clinical Investigation, vol. 121, no. 11, pp. 4210-4221, 2011.

[10] Y. M. Wang, M. Hu, Y. Wang et al., "Regulatory T cells in renal disease," International Journal of Clinical and Experimental Medicine, vol. 1, no. 4, pp. 294-304, 2008.

[11] A. K. Abbas, C. Benoist, J. A. Bluestone et al., "Regulatory T cells: recommendations to simplify the nomenclature," Nature Immunology, vol. 14, no. 4, pp. 307-308, 2013.
[12] E. M. Shevach and A. M. Thornton, "tTregs, pTregs, and iTregs: similarities and differences," Immunological Reviews, vol. 259, no. 1, pp. 88-102, 2014.

[13] M. M. Imanguli, E. W. Cowen, J. Rose et al., "Comparative analysis of $\mathrm{FoxP}^{+}$regulatory $\mathrm{T}$ cells in the target tissues and blood in chronic graft versus host disease," Leukemia, vol. 28, no. 10, pp. 2016-2027, 2014.

[14] Y. Wang, Y. Wang, Y. Wang et al., "Regulatory T cells require renal antigen recognition through the TCR to protect against injury in nephritis," International Journal of Clinical and Experimental Pathology, vol. 7, no. 1, pp. 38-47, 2014.

[15] S. Wei, I. Kryczek, and W. Zou, "Regulatory T-cell compartmentalization and trafficking," Blood, vol. 108, no. 2, pp. 426-431, 2006.

[16] B. D. Sather, P. Treuting, N. Perdue et al., "Altering the distribution of Foxp $3^{+}$regulatory $\mathrm{T}$ cells results in tissue-specific inflammatory disease," Journal of Experimental Medicine, vol. 204, no. 6, pp. 1335-1347, 2007.

[17] D. J. Campbell and M. A. Koch, "Phenotypical and functional specialization of FOXP3 ${ }^{+}$regulatory T cells," Nature Reviews Immunology, vol. 11, no. 2, pp. 119-130, 2011.

[18] D. A. A. Vignali, L. W. Collison, and C. J. Workman, "How regulatory T cells work," Nature Reviews Immunology, vol. 8, no. 7, pp. 523-532, 2008.

[19] J. Bodor, T. Bopp, M. Vaeth et al., "Cyclic AMP underpins suppression by regulatory T cells," European Journal of Immunology, vol. 42, no. 6, pp. 1375-1384, 2012.

[20] E. M. Shevach, "Mechanisms of foxp $3^{+}$T regulatory cellmediated suppression," Immunity, vol. 30, no. 5, pp. 636-645, 2009.

[21] N. Oberle, N. Eberhardt, C. S. Falk, P. H. Krammer, and E. SuriPayer, "Rapid suppression of cytokine transcription in human $\mathrm{CD} 4^{+} \mathrm{CD} 25^{-} \mathrm{T}$ cells by $\mathrm{CD} 4^{+}$Foxp $3^{+}$regulatory $\mathrm{T}$ cells: independence of IL- 2 consumption, TGF- $\beta$, and various inhibitors of TCR signaling," Journal of Immunology, vol. 179, no. 6, pp. 3578-3587, 2007.

[22] P. Pandiyan, L. Zheng, S. Ishihara, J. Reed, and M. J. Lenardo, "CD $4^{+} \mathrm{CD} 25^{+}$Foxp $3^{+}$regulatory T cells induce cytokine deprivation-mediated apoptosis of effector $\mathrm{CD}^{+} \mathrm{T}$ cells," Nature Immunology, vol. 8, no. 12, pp. 1353-1362, 2007.

[23] X. Ren, F. Ye, Z. Jiang, Y. Chu, S. Xiong, and Y. Wang, "Involvement of cellular death in TRAIL/DR5-dependent suppression induced by $\mathrm{CD} 4{ }^{+} \mathrm{CD} 25^{+}$regulatory T cells," Cell Death and Differentiation, vol. 14, no. 12, pp. 2076-2084, 2007.

[24] M. I. Garín, C.-C. Chu, D. Golshayan, E. Cernuda-Morollón, R. Wait, and R. I. Lechler, "Galectin-1: a key effector of regulation mediated by $\mathrm{CD} 4{ }^{+} \mathrm{CD} 25^{+} \mathrm{T}$ cells," Blood, vol. 109, no. 5, pp. 2058-2065, 2007.

[25] J. Kubach, P. Lutter, T. Bopp et al., "Human $\mathrm{CD} 4^{+} \mathrm{CD} 25^{+}$ regulatory T cells: proteome analysis identifies galectin-10 as a novel marker essential for their anergy and suppressive function," Blood, vol. 110, no. 5, pp. 1550-1558, 2007.

[26] W. J. Grossman, J. W. Verbsky, W. Barchet, M. Colonna, J. P. Atkinson, and T. J. Ley, "Human T regulatory cells can use the perforin pathway to cause autologous target cell death," Immunity, vol. 21, no. 4, pp. 589-601, 2004.

[27] D. C. Gondek, L.-F. Lu, S. A. Quezada, S. Sakaguchi, and R. J. Noelle, "Cutting edge: contact-mediated suppression by $\mathrm{CD} 4{ }^{+} \mathrm{CD} 25^{+}$regulatory cells involves a granzyme B-dependent, perforin-independent mechanism," Journal of Immunology, vol. 174, no. 4, pp. 1783-1786, 2005. 
[28] D. M. Sansom and L. S. K. Walker, "The role of CD28 and cytotoxic T-lymphocyte antigen-4 (CTLA-4) in regulatory Tcell biology," Immunological Reviews, vol. 212, pp. 131-148, 2006.

[29] X. Tai, F. Van Laethem, L. Pobezinsky et al., "Basis of CTLA-4 function in regulatory and conventional $\mathrm{CD}^{+}{ }^{+} \mathrm{T}$ cells," Blood, vol. 119, no. 22, pp. 5155-5163, 2012.

[30] B. Liang, C. Workman, J. Lee et al., "Regulatory T cells inhibit dendritic cells by lymphocyte activation gene- 3 engagement of MHC class II," The Journal of Immunology, vol. 180, no. 9, pp. 5916-5926, 2008.

[31] D. Q. Tran, D. D. Glass, G. Uzel et al., "Analysis of adhesion molecules, target cells, and role of IL-2 in human FOXP3 ${ }^{+}$ regulatory T cell suppressor function," Journal of Immunology, vol. 182, no. 5, pp. 2929-2938, 2009.

[32] M. Sarris, K. G. Andersen, F. Randow, L. Mayr, and A. G. Betz, "Neuropilin-1 expression on regulatory $\mathrm{T}$ cells enhances their interactions with dendritic cells during antigen recognition," Immunity, vol. 28, no. 3, pp. 402-413, 2008.

[33] K. Wing, Y. Onishi, P. Prieto-Martin et al., "CTLA-4 control over Foxp $3^{+}$regulatory T cell function,” Science, vol. 322, no. 5899, pp. 271-275, 2008.

[34] X. Yu, K. Harden, L. C. Gonzalez et al., "The surface protein TIGIT suppresses T cell activation by promoting the generation of mature immunoregulatory dendritic cells," Nature Immunology, vol. 10, no. 1, pp. 48-57, 2009.

[35] I. Shalev, K. M. Wong, K. Foerster et al., "The novel CD $4{ }^{+} \mathrm{CD} 25^{+}$ regulatory $\mathrm{T}$ cell effector molecule fibrinogen-like protein 2 contributes to the outcome of murine fulminant viral hepatitis," Hepatology, vol. 49, no. 2, pp. 387-397, 2009.

[36] I. Shalev, H. Liu, C. Koscik et al., "Targeted deletion of fgl2 leads to impaired regulatory $\mathrm{T}$ cell activity and development of autoimmune glomerulonephritis," Journal of Immunology, vol. 180, no. 1, pp. 249-260, 2008.

[37] H. Wang, K. Pan, and J.-C. Xia, "Interaction of indoleamine2,3-dioxyagnase and $\mathrm{CD} 4^{+} \mathrm{CD} 25^{+}$regulatory $\mathrm{T}$ cells in tumor immune escape," Chinese Journal of Cancer, vol. 28, no. 2, pp. 184-187, 2009.

[38] S. Deaglio, K. M. Dwyer, W. Gao et al., "Adenosine generation catalyzed by CD39 and CD73 expressed on regulatory T cells mediates immune suppression," The Journal of Experimental Medicine, vol. 204, no. 6, pp. 1257-1265, 2007.

[39] A. Ohta, R. Kini, A. Ohta, M. Subramanian, M. Madasu, and M. Sitkovsky, "The development and immunosuppressive functions of $\mathrm{CD}^{+} \mathrm{CD} 25^{+} \mathrm{FoxP}^{+}$regulatory $\mathrm{T}$ cells are under influence of the adenosine-A2A adenosine receptor pathway," Frontiers in Immunology, vol. 3, article 190, 2012.

[40] E. Panther, S. Corinti, M. Idzko et al., "Adenosine affects expression of membrane molecules, cytokine and chemokine release, and the T-cell stimulatory capacity of human dendritic cells," Blood, vol. 101, no. 10, pp. 3985-3990, 2003.

[41] G. R. Kinsey, R. Sharma, L. Huang et al., "Regulatory T cells suppress innate immunity in kidney ischemia-reperfusion injury," Journal of the American Society of Nephrology, vol. 20, no. 8, pp. 1744-1753, 2009.

[42] R. M. Monteiro, N. O. Camara, M. M. Rodrigues et al., "A role for regulatory T cells in renal acute kidney injury," Transplant Immunology, vol. 21, no. 1, pp. 50-55, 2009.

[43] M. T. Gandolfo, H. R. Jang, S. M. Bagnasco et al., "Foxp3 ${ }^{+}$ regulatory $\mathrm{T}$ cells participate in repair of ischemic acute kidney injury," Kidney International, vol. 76, no. 7, pp. 717-729, 2009.
[44] M. T. Gandolfo, H. R. Jang, S. M. Bagnasco et al., "Mycophenolate mofetil modifies kidney tubular injury and Foxp $3^{+}$ regulatory $\mathrm{T}$ cell trafficking during recovery from experimental ischemia-reperfusion," Transplant Immunology, vol. 23, no. 1-2, pp. 45-52, 2010.

[45] C. Jun, W. Ke, L. Qingshu et al., "Protective effect of $\mathrm{CD} 4{ }^{+} \mathrm{CD} 25^{\text {high }} \mathrm{CD} 127^{\text {low }}$ regulatory $\mathrm{T}$ cells in renal ischemiareperfusion injury," Cellular Immunology, vol. 289, no. 1-2, pp. 106-111, 2014.

[46] J. V. Bonventre, "Kidney ischemic preconditioning," Current Opinion in Nephrology and Hypertension, vol. 11, no. 1, pp. 4348, 2002.

[47] G. R. Kinsey, L. Huang, A. L. Vergis, L. Li, and M. D. Okusa, "Regulatory T cells contribute to the protective effect of ischemic preconditioning in the kidney," Kidney International, vol. 77, no. 9, pp. 771-780, 2010.

[48] W. Y. Cho, H. M. Choi, S. Y. Lee, M. G. Kim, H.-K. Kim, and S.-K. Jo, "The role of Tregs and CD11c ${ }^{+}$macrophages/dendritic cells in ischemic preconditioning of the kidney," Kidney International, vol. 78, no. 10, pp. 981-992, 2010.

[49] A. Grenz, H. Osswald, T. Eckle et al., "The reno-vascular A2B adenosine receptor protects the kidney from ischemia," PLoS Medicine, vol. 5, no. 6, article e137, 2008.

[50] H. Lee, D. Nho, H.-S. Chung et al., " $\mathrm{CD} 4{ }^{+} \mathrm{CD} 25^{+}$regulatory $\mathrm{T}$ cells attenuate cisplatin-induced nephrotoxicity in mice," Kidney International, vol. 78, no. 11, pp. 1100-1109, 2010.

[51] S.-Y. Lee, Y.-S. Lee, H.-M. Choi et al., "Distinct pathophysiologic mechanisms of septic acute kidney injury: role of immune suppression and renal tubular cell apoptosis in murine model of septic acute kidney injury," Critical Care Medicine, vol. 40, no. 11, pp. 2997-3006, 2012.

[52] E. Cho, J. H. Lee, H. J. Lim et al., "Soluble CD25 is increased in patients with sepsis-induced acute kidney injury," Nephrology, vol. 19, no. 6, pp. 318-324, 2014.

[53] X. Wan, W. J. Huang, W. Chen et al., "IL-10 deiciency increases renal ischemia-reperfusion injury," Nephron Experimental Nephrology, vol. 128, no. 1-2, pp. 37-45, 2014.

[54] G. R. Kinsey, L. Huang, K. Jaworska et al., "Autocrine adenosine signaling promotes regulatory $\mathrm{T}$ cell-mediated renal protection," Journal of the American Society of Nephrology, vol. 23, no. 9, pp. 1528-1537, 2012.

[55] K. Jaworska, J. Ratajczak, L. Huang et al., "Both PD-1 ligands protect the kidney from ischemia reperfusion injury," Journal of Immunology, vol. 194, no. 1, pp. 325-333, 2014.

[56] L. S. K. Walker, "Treg and CTLA-4: two intertwining pathways to immune tolerance," Journal of Autoimmunity, vol. 45, pp. 4957, 2013.

[57] L.-W. Lai, K.-C. Yong, and Y.-H. H. Lien, "Pharmacologic recruitment of regulatory $\mathrm{T}$ cells as a therapy for ischemic acute kidney injury," Kidney International, vol. 81, no. 10, pp. 983-992, 2012.

[58] H. Rabb, "The promise of immune cell therapy for acute kidney injury," Journal of Clinical Investigation, vol. 122, no. 11, pp. 38523854, 2012.

[59] C. H. June and B. R. Blazar, "Clinical application of expanded CD $4^{+} 25^{+}$cells," Seminars in Immunology, vol. 18, no. 2, pp. $78-$ 88,2006

[60] P. Li, Y. Gan, B.-L. Sun et al., "Adoptive regulatory T-cell therapy protects against cerebral ischemia," Annals of Neurology, vol. 74, no. 3, pp. 458-471, 2013. 
[61] T. J. Murphy, N. N. Choileain, Y. Zang, J. A. Mannick, and J. A. Lederer, "CD $4^{+} \mathrm{CD} 25^{+}$regulatory $\mathrm{T}$ cells control innate immune reactivity after injury," Journal of Immunology, vol. 174, no. 5, pp. 2957-2963, 2005.

[62] D. Mahajan, Y. Wang, X. Qin et al., " $\mathrm{CD} 4{ }^{+} \mathrm{CD} 25^{+}$regulatory T cells protect against injury in an innate murine model of chronic kidney disease," Journal of the American Society of Nephrology, vol. 17, no. 10, pp. 2731-2741, 2006.

[63] D. Wolf, K. Hochegger, A. M. Wolf et al., "CD $4^{+} \mathrm{CD} 25^{+}$ regulatory $\mathrm{T}$ cells inhibit experimental anti-glomerular basement membrane glomerulonephritis in mice," Journal of the American Society of Nephrology, vol. 16, no. 5, pp. 1360-1370, 2005.

[64] K. J. Scalapino, Q. Tang, J. A. Bluestone, M. L. Bonyhadi, and D. I. Daikh, "Suppression of disease in New Zealand Black/New Zealand White lupus-prone mice by adoptive transfer of ex vivo expanded regulatory T cells," Journal of Immunology, vol. 177, no. 3, pp. 1451-1459, 2006.

[65] X. Yang, H. Bai, Y. Wang et al., "Deletion of regulatory T cells supports the development of intestinal ischemia-reperfusion injuries," Journal of Surgical Research, vol. 184, no. 2, pp. 832$837,2013$.

[66] W. Liu, A. L. Putnam, Z. Xu-yu et al., "CD127 expression inversely correlates with FoxP3 and suppressive function of human $\mathrm{CD}^{+} \mathrm{T}$ reg cells," The Journal of Experimental Medicine, vol. 203, no. 7, pp. 1701-1711, 2006.

[67] P. Trzonkowski, M. Bieniaszewska, J. Juścińska et al., "First-inman clinical results of the treatment of patients with graft versus host disease with human ex vivo expanded $\mathrm{CD} 4^{+} \mathrm{CD} 25^{+} \mathrm{CD} 127^{-}$ T regulatory cells," Clinical Immunology, vol. 133, no. 1, pp. 2226, 2009.

[68] B. D. Singer, L. S. King, and F. R. D’Alessio, "Regulatory T cells as immunotherapy," Frontiers in Immunology, vol. 5, article 46, 2014.

[69] M. Di Ianni, F. Falzetti, A. Carotti et al., "Tregs prevent GVHD and promote immune reconstitution in HLA-haploidentical transplantation," Blood, vol. 117, no. 14, pp. 3921-3928, 2011.

[70] M. Di Ianni, F. Falzetti, A. Carotti et al., "Immunoselection and clinical use of $\mathrm{T}$ regulatory cells in HLA-haploidentical stem cell transplantation," Best Practice and Research: Clinical Haematology, vol. 24, no. 3, pp. 459-466, 2011.

[71] N. Marek-Trzonkowska, M. A. Wujtewicz, M. Myśliwiec et al., "Administration of $\mathrm{CD} 4{ }^{+} \mathrm{CD} 25^{\text {high }} \mathrm{CD} 127^{-}$regulatory $\mathrm{T}$ cells preserves $\beta$-cell function in type 1 diabetes in children," Diabetes Care, vol. 35, no. 9, pp. 1817-1820, 2012.

[72] C. G. Brunstein, J. S. Miller, Q. Cao et al., "Infusion of ex vivo expanded $\mathrm{T}$ regulatory cells in adults transplanted with umbilical cord blood: safety profile and detection kinetics," Blood, vol. 117, no. 3, pp. 1061-1070, 2011.

[73] X. Zhou, S. L. Bailey-Bucktrout, L. T. Jeker et al., "Instability of the transcription factor Foxp3 leads to the generation of pathogenic memory T cells in vivo," Nature Immunology, vol. 10, no. 9, pp. 1000-1007, 2009.

[74] N. Komatsu, M. E. Mariotti-Ferrandiz, Y. Wang, B. Malissen, H. Waldmann, and S. Hori, "Heterogeneity of natural Foxp $3^{+}$ T cells: a committed regulatory T-cell lineage and an uncommitted minor population retaining plasticity," Proceedings of the National Academy of Sciences of the United States of America, vol. 106, no. 6, pp. 1903-1908, 2009.
[75] K. Golab, D. Leveson-Gower, X.-J. Wang et al., "Challenges in cryopreservation of regulatory $\mathrm{T}$ cells (Tregs) for clinical therapeutic applications," International Immunopharmacology, vol. 16, no. 3, pp. 371-375, 2013.

[76] H. Lee, E.-J. Lee, H. Kim et al., "Bee venom-associated Th1/Th2 immunoglobulin class switching results in immune tolerance of NZB/W F1 murine lupus nephritis," American Journal of Nephrology, vol. 34, no. 2, pp. 163-172, 2011.

[77] H. Kim, G. Lee, S. Park et al., "Bee venom mitigates cisplatininduced nephrotoxicity by regulating $\mathrm{CD} 4{ }^{+} \mathrm{CD} 25^{+}$Foxp $3^{+}$regulatory T cells in mice," Evidence-based Complementary and Alternative Medicine, vol. 2013, Article ID 879845, 10 pages, 2013.

[78] H. Kim, H. Lee, G. Lee et al., "Phospholipase A2 inhibits cisplatin-induced acute kidney injury by modulating regulatory T cells by the CD206 mannose receptor," Kidney International, 2015.

[79] M.-G. Kim, S. Y. Lee, Y. S. Ko et al., " $\mathrm{CD} 4{ }^{+} \mathrm{CD} 25^{+}$regulatory $\mathrm{T}$ cells partially mediate the beneficial effects of FTY720, a sphingosine-1-phosphate analogue, during ischaemia/reperfusion-induced acute kidney injury," Nephrology Dialysis Transplantation, vol. 26, no. 1, pp. 111-124, 2011.

[80] K. E. Webster, S. Walters, R. E. Kohler et al., "In vivo expansion of $t$ reg cells with il-2-mab complexes: induction of resistance to eae and long-term acceptance of islet allografts without immunosuppression," The Journal of Experimental Medicine, vol. 206, no. 4, pp. 751-760, 2009.

[81] M.-G. Kim, T. Y. Koo, J.-J. Yan et al., "IL-2/anti-IL-2 complex attenuates renal ischemia-reperfusion injury through expansion of regulatory T cells," Journal of the American Society of Nephrology, vol. 24, no. 10, pp. 1529-1536, 2013.

[82] B. Baban, J. Y. Liu, and M. S. Mozaffari, "Aryl hydrocarbon receptor agonist, leflunomide, protects the ischemic-reperfused kidney: role of Tregs and stem cells," The American Journal of Physiology-Regulatory Integrative and Comparative Physiology, vol. 303, no. 11, pp. R1136-R1146, 2012.

[83] E. Gonzalez-Rey, M. A. Gonzalez, N. Varela et al., "Human adipose-derived mesenchymal stem cells reduce inflammatory and $\mathrm{T}$ cell responses and induce regulatory $\mathrm{T}$ cells in vitro in rheumatoid arthritis," Annals of the Rheumatic Diseases, vol. 69, no. 1, pp. 241-248, 2010.

[84] S. A. Patel, J. R. Meyer, S. J. Greco, K. E. Corcoran, M. Bryan, and P. Rameshwar, "Mesenchymal stem cells protect breast cancer cells through regulatory T cells: role of mesenchymal stem cellderived TGF- $\beta$," Journal of Immunology, vol. 184, no. 10, pp. 5885-5894, 2010.

[85] D. Zuo, X. Liu, Z. Shou et al., "Study on the interactions between transplanted bone marrow-derived mesenchymal stem cells and regulatory T cells for the treatment of experimental colitis," International Journal of Molecular Medicine, vol. 32, no. 6, pp. 1337-1344, 2013.

[86] J. Hu, L. Zhang, N. Wang et al., "Mesenchymal stem cells attenuate ischemic acute kidney injury by inducing regulatory T cells through splenocyte interactions," Kidney International, vol. 84, no. 3, pp. 521-531, 2013.

[87] B. Liu, X. Wu, B. Liu et al., "MiR-26a enhances metastasis potential of lung cancer cells via AKT pathway by targeting PTEN," Biochimica et Biophysica Acta-Molecular Basis of Disease, vol. 1822, no. 11, pp. 1692-1704, 2012. 
[88] S. Liang, W. Wang, and X. Gou, "MicroRNA 26a modulates regulatory $\mathrm{T}$ cells expansion and attenuates renal ischemiareperfusion injury," Molecular Immunology, vol. 65, no. 2, pp. 321-327, 2015

[89] A. Javeed, B. Zhang, Y. Qu et al., “The significantly enhanced frequency of functional $\mathrm{CD} 4^{+} \mathrm{CD} 25^{+} \mathrm{Foxp}^{+} \mathrm{T}$ regulatory cells in therapeutic dose aspirin-treated mice," Transplant Immunology, vol. 20, no. 4, pp. 253-260, 2009.

[90] N. A. Forward, S. J. Furlong, Y. Yang, T.-J. Lin, and D. W. Hoskin, "Signaling through TLR7 enhances the immunosuppressive activity of murine $\mathrm{CD} 4{ }^{+} \mathrm{CD} 25^{+} \mathrm{T}$ regulatory cells," Journal of Leukocyte Biology, vol. 87, no. 1, pp. 117-125, 2010.

[91] A. E. Pedersen, K. Holmstrøm, F. Jørgensen, S. S. Jensen, and M. Gad, "Development of assay platforms for in vitro screening of Treg modulating potential of pharmacological compounds," Immunopharmacology and Immunotoxicology, vol. 37, no. 1, pp. 63-71, 2015. 


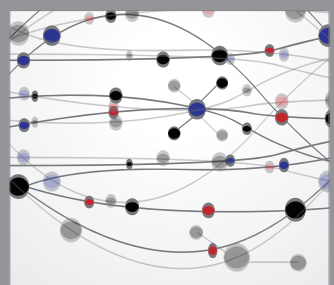

The Scientific World Journal
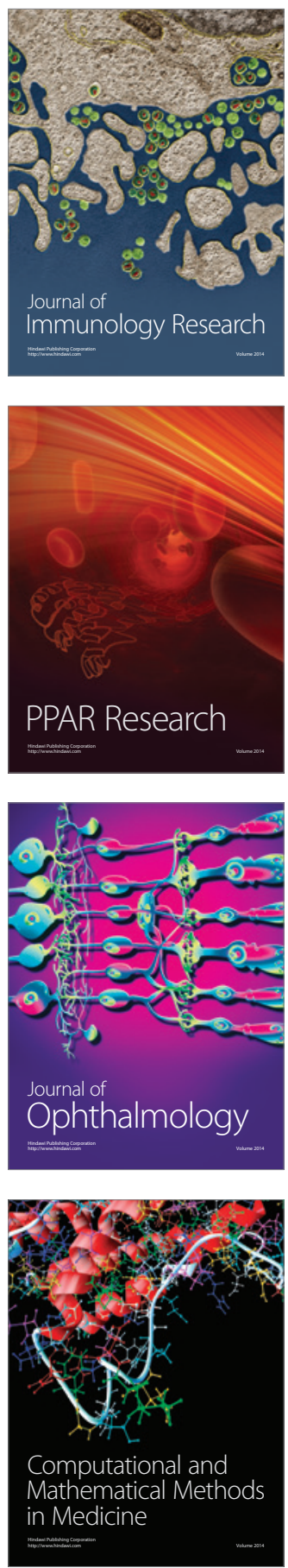

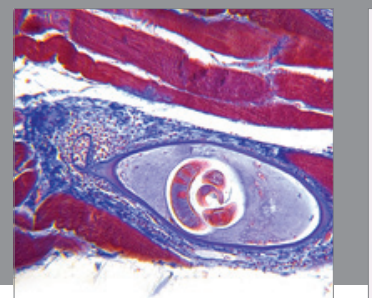

Gastroenterology

Research and Practice
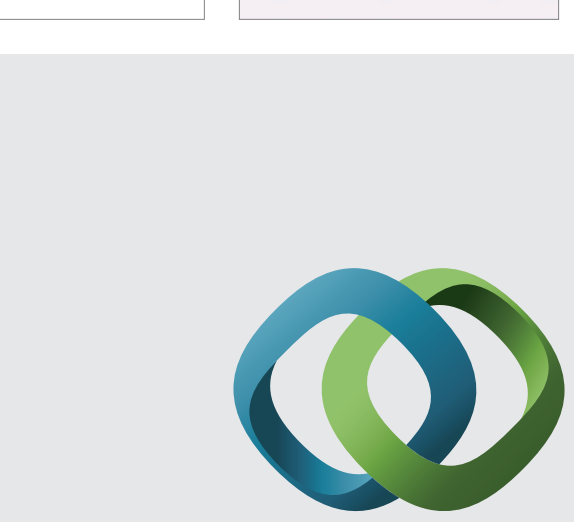

\section{Hindawi}

Submit your manuscripts at

http://www.hindawi.com
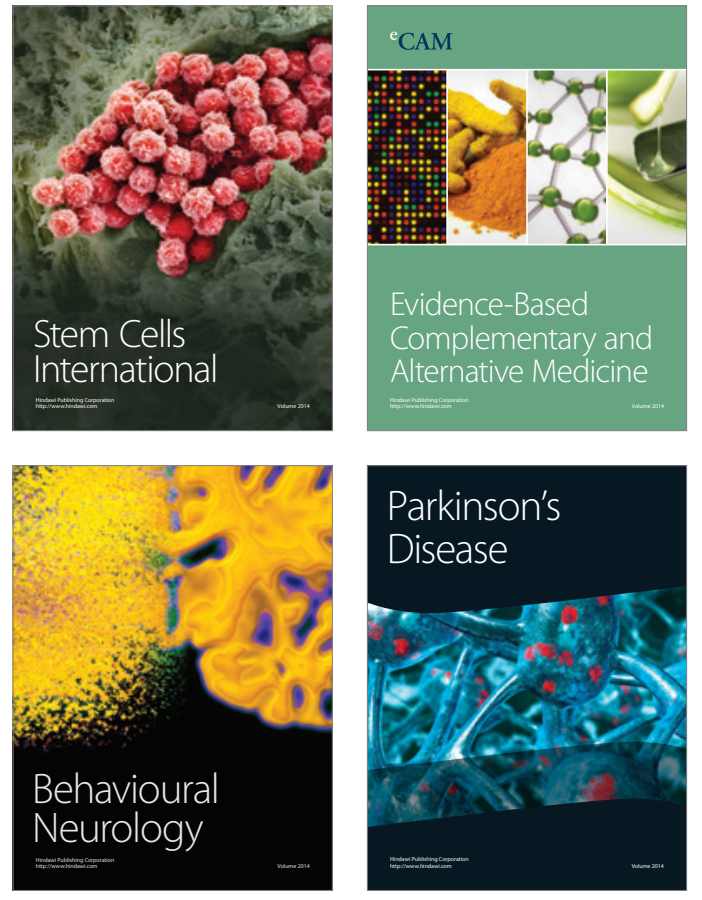
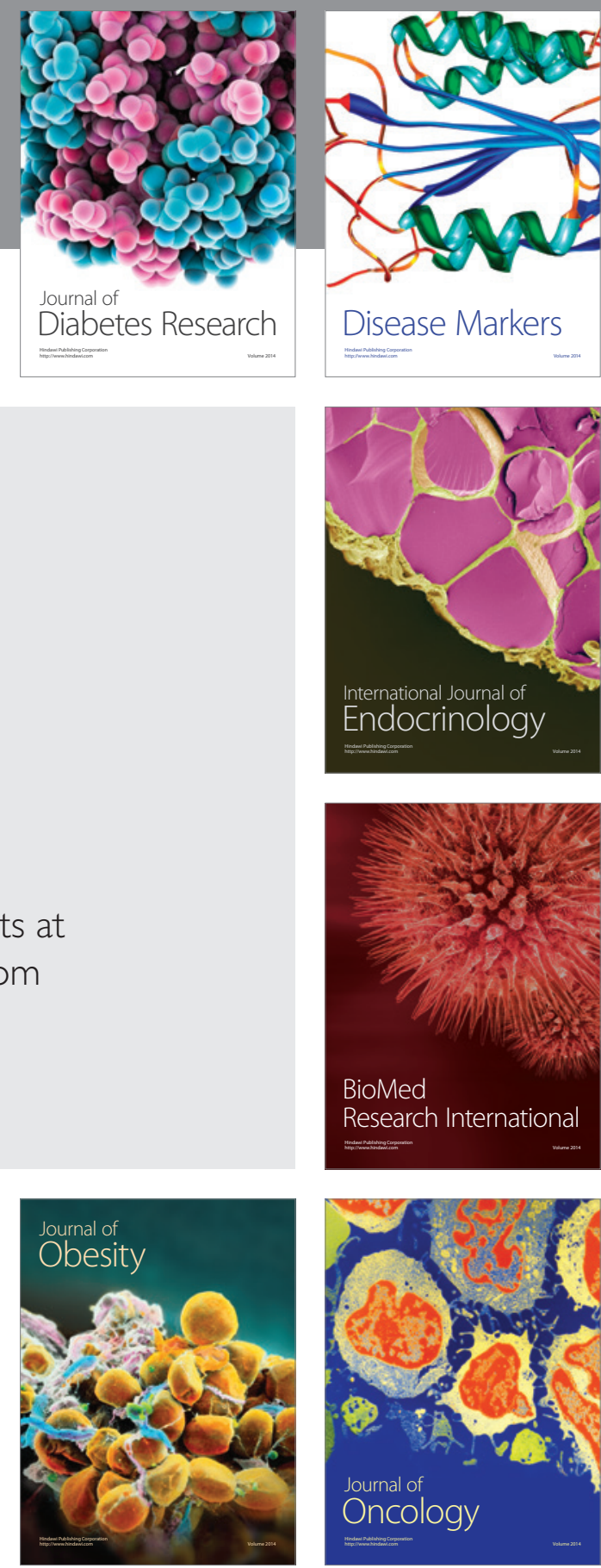

Disease Markers
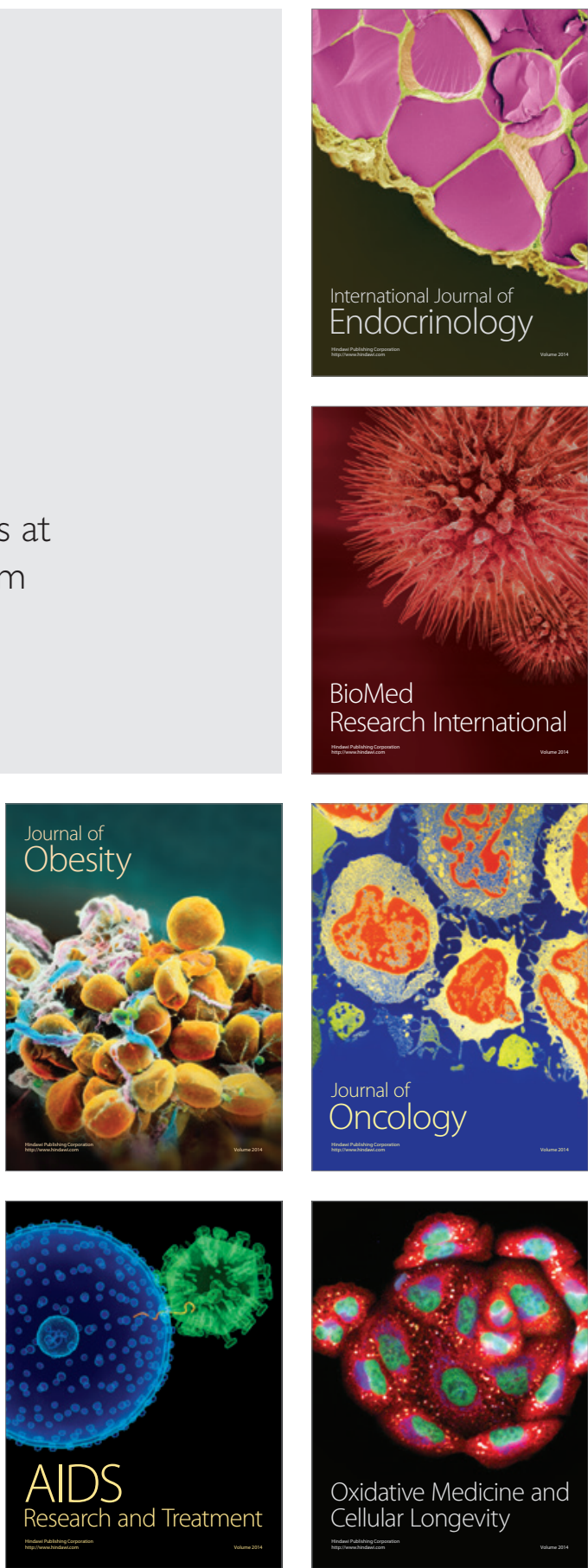